\title{
HEAT TRANSFER ENHANCEMENT FROM A HEATED PLATE WITH HEMISPHERICAL CONVEX DIMPLES BY FORCED CONVECTION ALONG WITH A CROSS FLOW JET IMPINGEMENT
}

\author{
P. PATRO* \\ Department of Mechanical Engineering \\ VSSUT, Burla, Odisha, INDIA -768018 \\ E-mail: ppatro123@yahoo.com \\ S. GARNAYAK \\ School of Energy Science and Engineering \\ IIT Kharagpur, INDIA-721302
}

\begin{abstract}
In the present study, heat transfer from a small three dimensional rectangular channel due to turbulent jet impinging from a nozzle normal to the main flow at the inlet has been investigated. Hemispherical convex dimples are attached to the bottom plate from where heat transfer calculations are to be performed. Numerical simulations were performed using the finite volume method with SST $k-\omega$ turbulence model. The duct and nozzle Reynolds number are varied in the range of $10000 \leq \operatorname{Re}_{D} \leq 50000$ and $6000 \leq \operatorname{Re}_{d} \leq 12000$, respectively. Different nozzle positions $(X / D=10.57,12.88,15.19)$ along the axial direction of the rectangular duct have been considered. It has been found that higher heat transfer is observed at $X / D=10.57$ as compared to the other positions. The heat transfer enhancements with and without cross-flow effects have also been compared. It has been shown that the heat transfer rate with cross-flow is found to be much higher than that without crossflow. Also, the effect of dimples on the heated surface on heat transfer was investigated. The heat transfer is found to be greater in the presence of a dimpled surface than a plane surface.
\end{abstract}

Key words: heat transfer enhancement, jet impingement, convex dimpled surface, SST k-w model, cross flow.

\section{Introduction}

The main focus of the present study is heat transfer from a mini-channel. One of the most prominent industrial applications for this type of studies is electronics cooling. In electronic devices, very small area is available for heat transfer. So, cooling of electronic devices is a great challenge owing to higher operational speed and higher power density. Simple jet impingement or forced convection is not sufficient to transfer the required heat to safeguard the electronic components. Many researchers have investigated heat transfer prediction through mini-channels experimentally as well as numerically. Forced convective cooling is very effective and widely used in many applications [1-3]. Sudo et al. [4, 5] studied single-phase convective heat transfer characteristics between upward and downward flows through a narrow rectangular channel $(2.25 \times 40$ $\mathrm{mm}$ ) by varying the Reynolds number (Re) in the range from 100 to 40.000 and Prandtl number (Pr) from 3.5 to 10 . They observed that heat transfer in the downward flows has a lower heat transfer coefficient than that for the upward flows. Use of fins on the heated surface along with the forced convection augments more heat transfer in comparison to convection cooling only. Dewan et al. [6-7] performed a computational study for the thermal analysis of a rectangular channel with circular pin fins and tapered fins $\left(2^{0}\right.$ and $\left.4^{0}\right)$. They showed that RNG $k-\varepsilon$ turbulence model with standard wall functions is suitable for this type of flows. It is also

\footnotetext{
* To whom correspondence should be addressed
} 
shown that at low inlet velocities $(<5 \mathrm{~m} / \mathrm{s})$, straight circular pin fins provide more hear transfer. But, for inlet velocities more than $5 \mathrm{~m} / \mathrm{s}$, tapered fin with $2^{0}$ taper angle provide better heat transfer. Re in the range 550 to 685 are the best for operating a compact heat exchanger. Wang et al. [8] performed experiments as well as numerical simulations for the flow and heat transfer characteristics inside a rectangular channel with different shaped fins (i.e. circular, elliptical and drop-shaped). They summarized their findings as "more streamlined drop-shaped pin fins were better at delaying or suppressing separation of the flow passing through them, which decreased the aerodynamic penalty compared to circular pin fins. The heat transfer enhancement of the drop-shaped pin fins was less than that of the circular pin fins. In terms of specific performance parameters, drop-shaped pin fins are a promising alternative configuration to circular pin fins". Chyu et al. [9] investigated the cubic- and diamond-shaped pin fin arrays for inline as well as staggered arrangements. They found that heat transfer is higher in cubic pin fin arrays and the diamond pin fin array induced high pressure losses for both type of configurations.

Juckerman and Lior [10] showed that compared with conventional forced convection cooling, jet impingement produces heat transfer coefficients that are up to three times higher at a given maximum flow speed. This happens because the impingement boundary layers are much thinner, and most often the flow after the impingement makes the surrounding fluid turbulent. The impingement cooling approach also offers a compact hardware arrangement. So, it is suitable for use in mini-channels. Many research [11-16] studies show that heat transfer augmentation occurred by the jet impingement on a heated surface. The heat transfer performance of an array of jet impinging on a surface with dimples has been investigated experimentally by Kanokjaruvijit and Martinez-Botas [17]. They showed that the impingement heat transfer performance was better at larger nozzle distance. Heat transfer is augmented when a plane surface is replaced with the concave and convex surfaces [18].

In practical applications, a hybrid cooling method comprising of a turbulent flow at inlet along with a cross flow from a nozzle at the top wall is used. Such interaction results in a rather complex flow field by the generation of coherent vortical structures, and these vortices play a dominant role in the mixing of fluids [19]. As suggested by Sparrow et al. [20], the leading parameters determining the jet impingement heat transfer in cross flow are (a) the velocity ratio (ratio of jet velocity and cross flow velocity, nozzle-to-surface spacing and the jet diameter. Air impingement cooling with a circular jet in a cross flow was investigated experimentally [21-22]. They found that the heat transfer coefficients were lower than those reported in the literature for an impinging jet in the absence of cross flow. Enhancement of heat transfer from a small rectangular channel with different surface protrusions (i.e. rectangular, triangular and trapezoidal ribs) with cross flow approach was investigated numerically by Barik et al. [23]. They found that the heat transfer enhancement rate is greater in triangular ribs compared to other two ribs. Jet impingement heat transfer by using a rib with cross flow approach using liquid crystal thermography was investigated experimentally by Wang et al. [24]. They showed that at a lower velocity ratio (ratio of nozzle velocity and inlet velocity), a more pronounced effect on heat transfer enhancement was found.

From the above discussion, it is clear that the heat transfer enhancement from a hemispherical convex dimpled surface with cross flow approach has not yet drawn much attention of researchers. In the present study, therefore, an attempt has been made to investigate the heat transfer augmentation by implementing the above hybrid scheme. The jet position, duct and jet Reynolds number have been varied to study their effects on the heat transfer from a heated surface.

\section{Computational domain and mathematical modelling}

A square duct has been considered in the present investigation (Fig.1). At the inlet, air enters at a velocity, $U_{\text {in }}$ and atmospheric temperature, $T_{\infty}$. A square nozzle is placed at the top surface of the duct, which impinges air to the main duct flow. This cross flow pattern will enhance the mixing which in turn increases the heat transfer from the heated surface (bottom surface of the duct). The heated surface (constant temperature condition) contains convex dimples (dimensions shown in Fig.2) to study the effect of the dimples on heat transfer. An extra length of 10 times the hydraulic diameter of the duct has been considered upstream as well as downstream to ensure a fully developed flow and to reduce the effect of backflow at the 
duct exit, respectively. The computational domain is meshed as shown in Fig.3. The meshes on the duct inlet, nozzle inlet, bottom surface with convex dimple surface and pressure outlet are shown for the sake of clarity. Unstructured meshes have been adopted to mesh the entire surface. The $X$-axis passes through the centre of the duct. The square cross section has one side, $b=0.005 \mathrm{~m}$

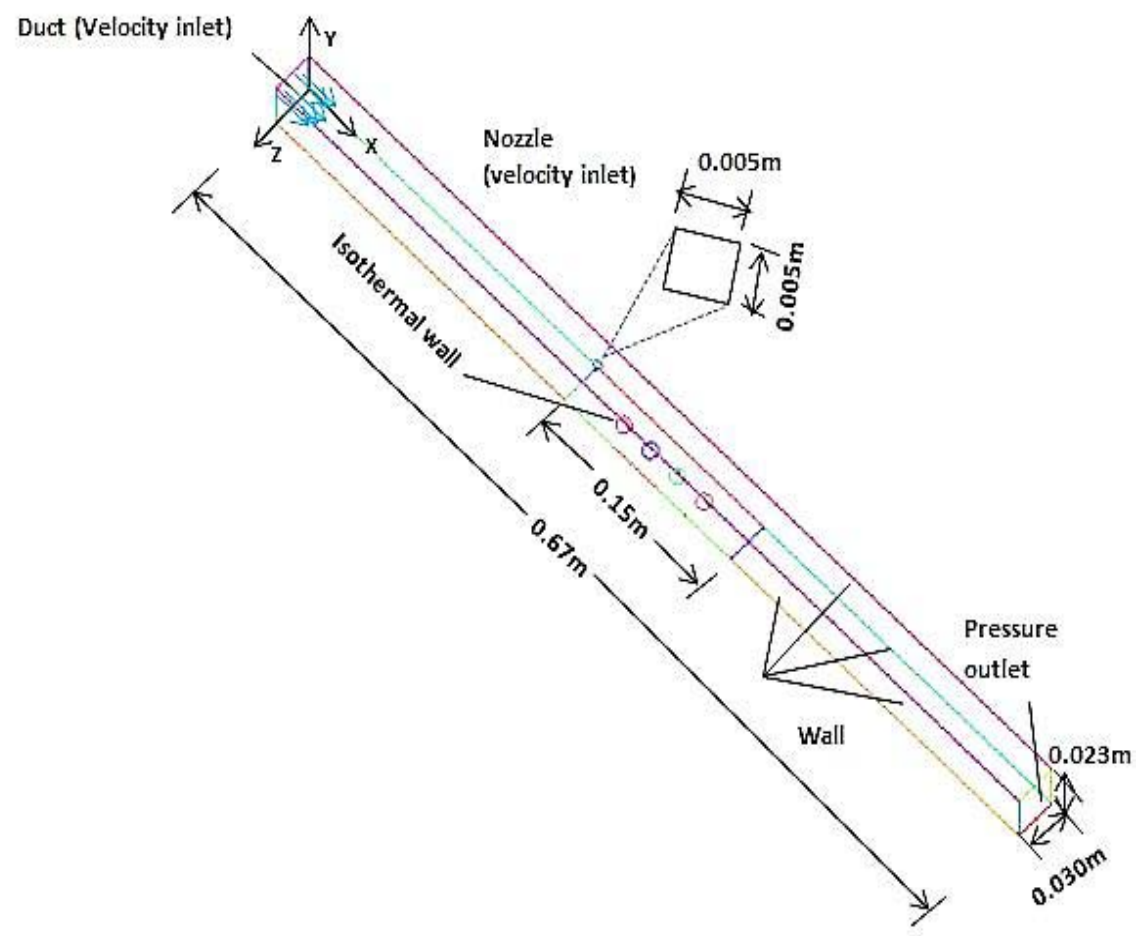

Fig.1. Schematic diagram of the computational domain with different boundary conditions.
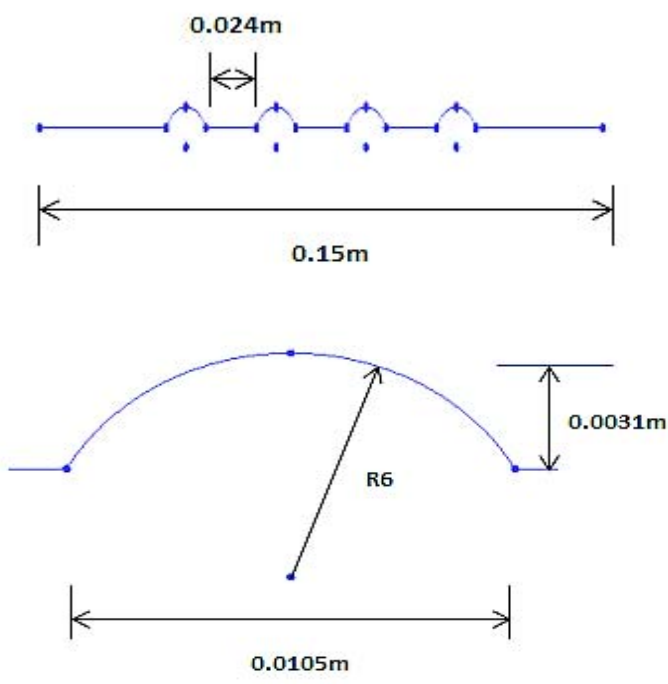

Fig.2. Convex dimple surface geometry. 


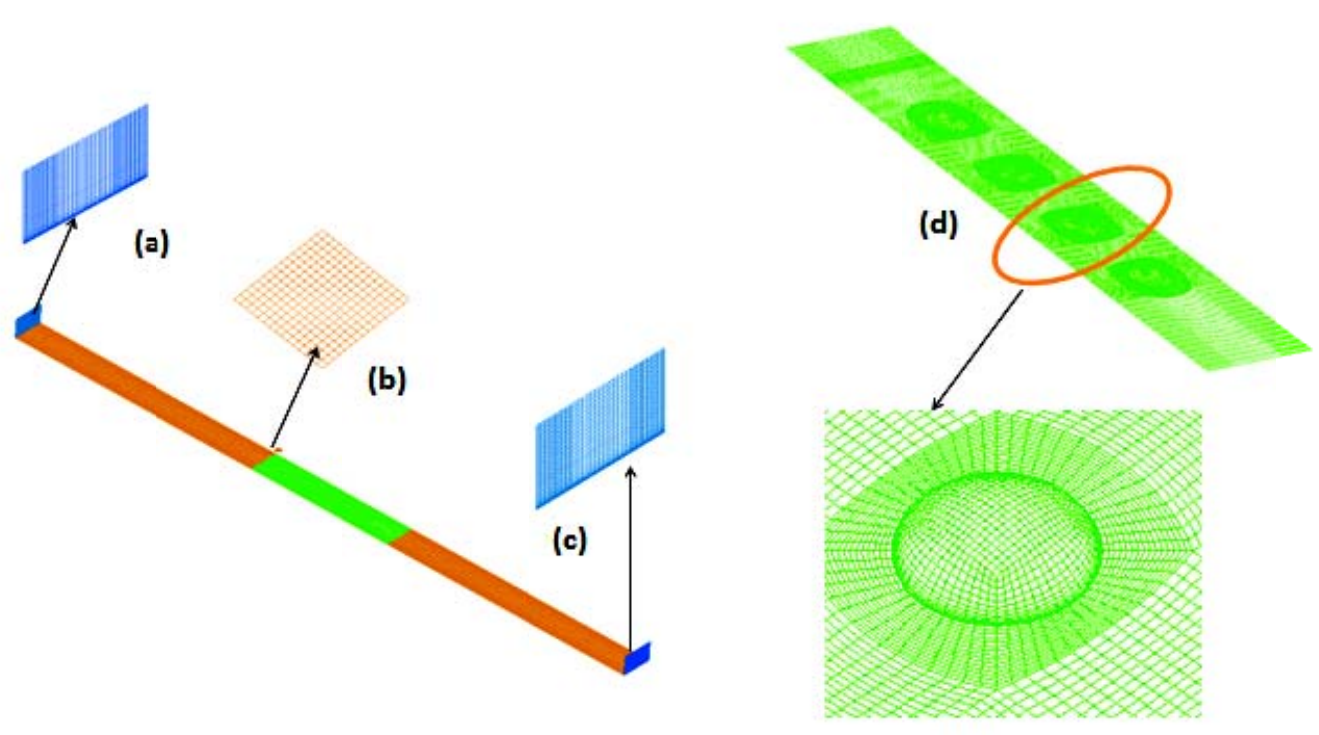

(e)

Fig.3. Meshing of a computational domain (a) duct inlet (b) nozzle inlet (c) duct outlet (d) isothermal wall (e) expanded view of the mesh at the convex dimple surface.

\subsection{Governing equations}

Simulations are performed for a steady, 3-D and turbulent incompressible flow. Reynolds timeaveraged equations for continuity, momentum, energy are written as follows:

Continuity equation

$$
\frac{\partial U_{i}}{\partial x_{i}}=0
$$

Momentum equation

$$
\rho U_{j} \frac{\partial U_{i}}{\partial x_{j}}=-\frac{\partial P}{\partial x_{i}}+\frac{\partial}{\partial x_{j}}\left(2 \mu S_{i j}-\rho \overline{U_{i}^{\prime} U_{j}^{\prime}}\right),
$$

Energy equations

$$
\rho U_{j} \frac{\partial T}{\partial x_{j}}=\frac{\partial}{\partial x_{j}}\left(\frac{\lambda}{c_{p}} \frac{\partial T}{\partial x_{j}}-\rho \overline{T^{\prime} u U_{j}}\right) .
$$

The strain rate tensor is defined as

$$
S_{i j}=\frac{1}{2}\left(\frac{\partial U_{i}}{\partial x_{j}}+\frac{\partial U_{j}}{\partial x_{i}}\right)
$$


where $\mu, \lambda$ and $C_{p}$ represent the molecular viscosity, thermal conductivity and specific heat at constant pressure for the working fluid (air). Here, air is assumed to be incompressible. $P$ is the mean pressure, $T$ is the mean temperature and $U_{i}$ is the mean velocity. $T$ and $U_{i}^{\prime}$ are the fluctuating temperature and velocity, respectively. The Reynolds stress $\left(-\rho \overline{U_{i}^{\prime} U_{j}^{\prime}}\right)$ and the turbulent heat flux $\left(-\rho \overline{U_{i}^{\prime} T^{\prime}}\right)$ terms are appeared due to Reynolds time averaging and these terms need to be closed by using the appropriate turbulence model. In the present study, the SST $k-\omega$ model has been implemented. The Reynolds stress is modelled as

$$
-\rho \overline{U_{i}^{\prime} U_{j}^{\prime}}=2 \mu_{t} S_{i j}-\frac{2}{3} \rho k \delta_{i j}
$$

where $k$ denotes the turbulent kinetic energy and $\mu_{t}$ represents the eddy viscosity.

The turbulent heat flux is defined as

$$
-\rho \overline{U_{i}^{\prime} T^{\prime}}=\frac{\mu_{t}}{\operatorname{Pr}_{t}} \frac{\partial T}{\partial x_{i}}
$$

Here, $\operatorname{Pr}_{t}$ denotes the turbulent Prandtl number. Expressions for the turbulence kinetic energy $(k)$ and specific dissipation of turbulence kinetic energy $(\omega)$ are written as follows

$$
\begin{aligned}
& \frac{\partial}{\partial x_{i}}\left(\rho k U_{i}\right)=\frac{\partial}{\partial x_{j}}\left[\left(\mu+\frac{\mu_{t}}{\sigma_{\kappa}}\right) \frac{\partial k}{\partial x_{j}}\right]+\min \left(P_{\kappa}, 10 \rho \beta^{*} k \omega\right)-\rho \beta^{*} k \omega, \\
& \frac{\partial}{\partial x_{i}}\left(\rho \omega U_{i}\right)=\frac{\partial}{\partial x_{j}}\left[\left(\mu+\frac{\mu_{t}}{\sigma_{\kappa}}\right) \frac{\partial \omega}{\partial x_{j}}\right]+\frac{\alpha \omega}{k} P_{\kappa}-\rho \beta \omega^{2}+2\left(1-F_{l}\right) \frac{\rho \sigma_{\omega, 2}}{\omega} \frac{\partial k}{\partial x_{j}} \frac{\partial \omega}{\partial x_{j}} .
\end{aligned}
$$

The eddy viscosity is modeled as

$$
\mu_{t}=\rho \frac{k}{\omega} \frac{1}{\max \left(\frac{1}{\alpha^{*}}, \frac{S F_{2}}{a_{1} \omega}\right)} .
$$

The modulus of the mean rate of the strain tensor $S$ is defined as $\sqrt{ }\left(2 S_{i j} S_{i j}\right)$.

The turbulent viscosity is damped by the coefficient $\alpha^{*}$.

$$
\begin{aligned}
& \alpha^{*}=\alpha_{\infty}^{*}\left(\frac{\alpha_{0}^{*}+\frac{\mathrm{Re}_{t}}{R_{k}}}{1+\frac{\mathrm{Re}_{t}}{R_{k}}}\right), \\
& \alpha_{0}^{*}=\frac{\beta_{i}}{3} \\
& \operatorname{Re}_{t}=\frac{\rho k}{\mu \omega}
\end{aligned}
$$


The blending functions, $F_{1}$ and $F_{2}$ are given as $F_{1}=\tanh \left(\varnothing_{1}^{4}\right)$ and $F_{2}=\tanh \left(\varnothing_{2}^{2}\right)$ $\varnothing_{1}=\min \left[\max \left(\sqrt{\kappa}_{\kappa} / 0.09 \omega y, 500 \mu / \rho y^{2} \omega\right), 4 \rho \kappa / \sigma_{\omega, 2} D_{\omega}{ }^{+} y\right], \varnothing_{2}=\max \left[2 \sqrt{ }_{\kappa} / 0.09 \omega y, 500 \mu / \rho y^{2} \omega\right]$.

In $\varnothing_{1}$ and $\varnothing_{2}$ terms, $y$ is the distance to the next surface. The positive portion of cross-diffusion is represented by $D_{\omega}^{+}=\max \left[2 \rho / \sigma_{\omega, 2} \omega \partial \kappa / \partial x_{j} \partial \omega / \partial x_{j}, 10^{-10}\right]$. The production of turbulence kinetic energy is defined as

$$
P_{\kappa}=-\rho \overline{U_{i}^{\prime} U_{j}^{\prime}} \frac{\partial U_{i}}{\partial x_{i}}
$$

For an incompressible flow, term $\beta^{*}$ in Eq.(2.7) is equal to $\beta_{1}^{*}$ which is defined as follows

$$
\beta_{1}^{*}=\beta_{\infty}^{*}\left(\frac{4 / 15+\left(\mathrm{Re}_{t} / R_{\beta}\right)^{4}}{1+\left(\mathrm{Re}_{t} / R_{\beta}\right)^{4}}\right)
$$

Closure constants in SST $k-\omega$ turbulence model are given as follows

$$
\begin{aligned}
& \alpha_{\infty}^{*}=1, \quad \beta_{\infty}^{*}=0.09, \quad \beta_{i}=0.075, \quad \sigma_{\kappa, l}=1.176, \quad, 1=2, \quad \sigma_{\kappa, 2}=1, \\
& \sigma_{\omega, 2}=1.168, \quad R_{\kappa}=6, \quad a_{1}=0.31 \quad \text { and } \quad R_{\beta}=8 .
\end{aligned}
$$

\subsection{Boundary conditions}

\section{At duct inlet}

$$
U=U_{\text {in }}, \quad T=T_{\infty}=300 \mathrm{~K} .
$$

\section{At nozzle exit}

$$
V=-V_{i n}, \quad T=T_{\infty}=300 \mathrm{~K} .
$$

The turbulence intensity at the duct inlet and nozzle exit is set as $2 \%$.

$U_{i n}$ and $V_{i n}$ are calculated from the value of the Reynolds number at the duct inlet and nozzle exit.

The duct Reynolds number, $\operatorname{Re}_{D}=\frac{\rho U_{i n} D}{\mu}$.

The nozzle Reynolds number, $\operatorname{Re}_{d}=\frac{\rho V_{\text {in }} d}{\mu}$.

Here, $D$ and d are the hydraulic diameter of the duct and nozzle, respectively.

\section{At adiabatic walls}

$$
U=V=W=0 .
$$

Heat flux for an adiabatic wall is zero. So, the temperature gradient along the normal direction is zero. The mathematical representation of this boundary condition is 


$$
q=\lambda \frac{\partial T}{\partial n}=0
$$

\section{At heated wall}

$$
U=V=W=0, \quad T=T_{w}=373 k .
$$

Here $U, V$ and $W$ are the velocity components in the $x, y$, and $z$ direction, respectively.

\section{At duct outlet}

$$
P=P_{\infty}, \quad \text { and } \quad T=T_{\infty}
$$

where, $P_{\infty}$ and $T_{\infty}$ are the ambient pressure and temperature, respectively. The standard wall function of Launder and Spalding [25] has been used to link the solution variables at near-wall cells to the corresponding quantities on the wall.

\section{Numerical methodology}

The commercial CFD package ANSYS-Fluent 15.0 was used for the numerical simulation of the present problem. The diffusive terms of the governing equations were discretized using the second-order central difference scheme and the convective terms were discretized using the second order upwind scheme. For pressure-velocity coupling, SIMPLE algorithm has been employed. The convergence criteria for all the equations except the energy equation are set to $10^{-3}$. A stricter convergence criterion of $10^{-5}$ has been employed for energy equation. The SST $k-\omega$ turbulence model is more appropriate for modelling the flows, which involve flow separation and reattachment due to the adverse pressure gradient. In the present study, the flow separation and its reattachment is expected because of the dimpled surface. Therefore, the SST $k-\omega$ model is preferred over the standard $k-\omega$ and $k-\varepsilon$ models. To model the principal stress through the SST $k-\omega$ model, the turbulent viscosity has been modified by incorporating blending functions $\left(F_{l}\right.$ and $\left.F_{2}\right)$ and mean strain rate.

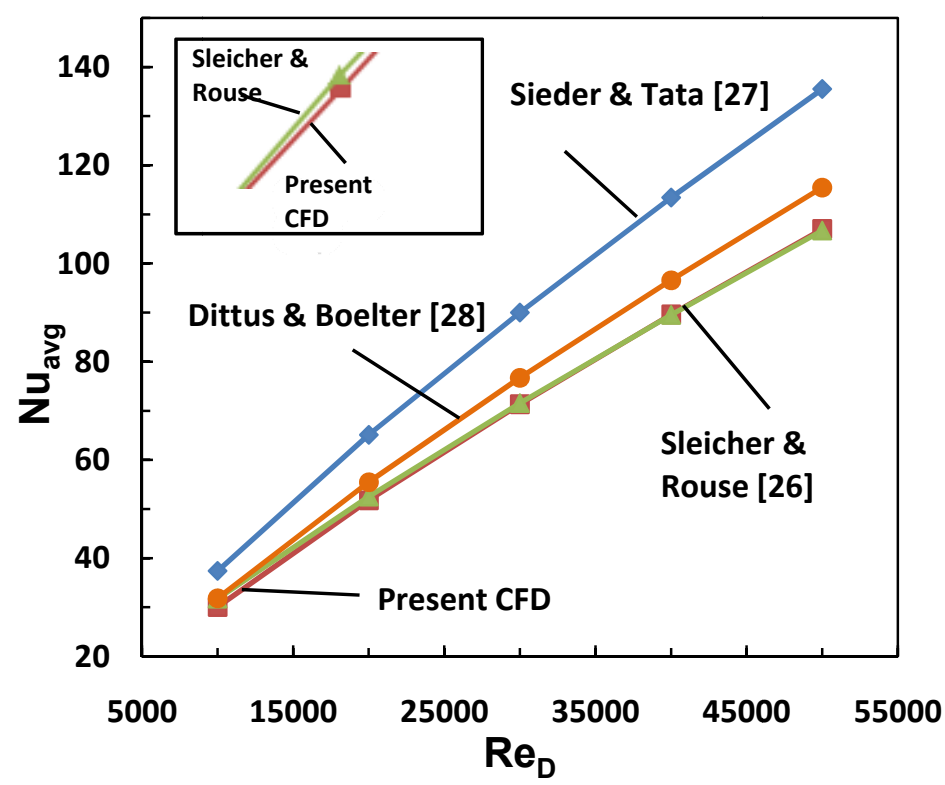

Fig.4. Average Nu vs. Re: Comparison between present CFD and existing correlations. 
The present numerical scheme is validated with Sleicher and Rouse [26] correlation, Sielder and Tate [27] correlation as well as Dittus-Boelter correlation [28] for a turbulent flow in a 3D pipe (diameter $0.026 \mathrm{~m}$ and length $0.67 \mathrm{~m}$ ). A grid sensitivity test has also been carried out and it is found that a grid size of 42.800 cells predicted the surface Nusselt number reasonably well with the correlation by Sleicher and Rouse [26] as shown in Fig.4.

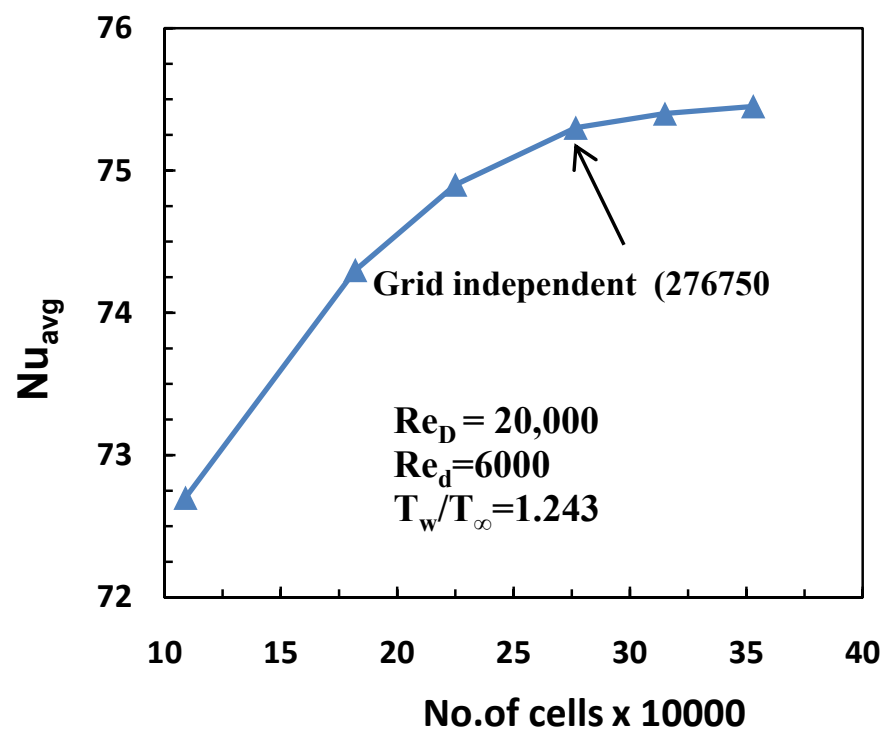

Fig.5. Effect of number of cells on average Nusselt number.

A grid sensitivity test for the present computational domain (i.e. dimpled surface in the presence of a cross flow jet) is shown in Fig.5. It can be seen that average Nusselt number $\left(N u_{\text {avg }}\right)$ is increased by $0.53 \%$ as the number of cells increases from 225.000 to 276.750 . The increase in the Nusselt number is insignificant $(0.14 \%)$ on further increasing the numbers of cells. Thus, 276.750 cells are used as a grid independent mesh for the present study.

\section{Results and discussion}

In the present study, the heated surface with a convex dimpled surface as well as plane heated surface (without dimples) is compared for the thermal performance. The major parameters affecting the heat transfer from the heated surface are the axial position of the nozzle on the top wall (X/D), duct Reynolds number $\left(\operatorname{Re}_{D}=\frac{\rho U_{m} D}{\mu}\right)$ and nozzle Reynolds number $\left(\operatorname{Re}_{d}=\frac{\rho u_{m} d}{\mu}\right)$. Here, $D$ and $d$ are the hydraulic diameters of the duct and nozzle, respectively. Also, $U_{m}$ and $u_{m}$ are the mean flow velocities in the duct and nozzle, respectively.

For a rectangular cross section of width $\mathbf{a}$ and height $\mathbf{b}$, hydraulic diameter $=2 a b /(a+b)$

The local heat transfer coefficient has been calculated as

$$
h=\frac{q_{w}}{T_{w}-T_{m}}=\frac{-K\left(\frac{\partial T}{\partial y}\right)_{\text {at wall }}}{T_{w}-T_{m}}
$$

where $q_{w}$ is the wall heat flux, $K$ is the thermal conductivity of air and $T_{m}$ is the bulk temperature defined as 


$$
T_{m}=\frac{\int_{0}^{D / 2} \rho C_{p} U_{m} T r d r}{\int_{0}^{D / 2} \rho C_{p} U_{m} r d r} .
$$

Here,

$$
r=D / 2
$$

The overall heat transfer coefficient is calculated as

$$
h_{\text {avg }}=\frac{1}{L} \int h d x
$$

where $h$ and $x$ are the local heat transfer coefficient and axial coordinate, respectively.

The average Nusselt number is expressed as

$$
\mathrm{Nu}=\frac{h_{a v g} D}{K}
$$

\subsection{Effect of nozzle position on Nusselt number for convex dimple surface}

Different axial locations of the nozzle (position 1: $X / D=10.57$, position 2: $X / D=12.88$ and position 3: $X / D=15.19)$ are considered. Figure 6 shows the variation of average Nusselt number $\left(\mathrm{Nu}_{\text {avg }}\right)$ with duct Reynolds numbers $\left(\operatorname{Re}_{D}\right)$ for different nozzle positions. It is shown that the Nusselt number has been increased with the duct Reynolds number. It is due to forced convection effect. As the velocity of the fluid increases, turbulence eddies are formed where the boundary layer breaks away from the wall and mixes with the bulk fluid. Mixing becomes more intense as fluid velocity increases and hence, heat transfer also increases.

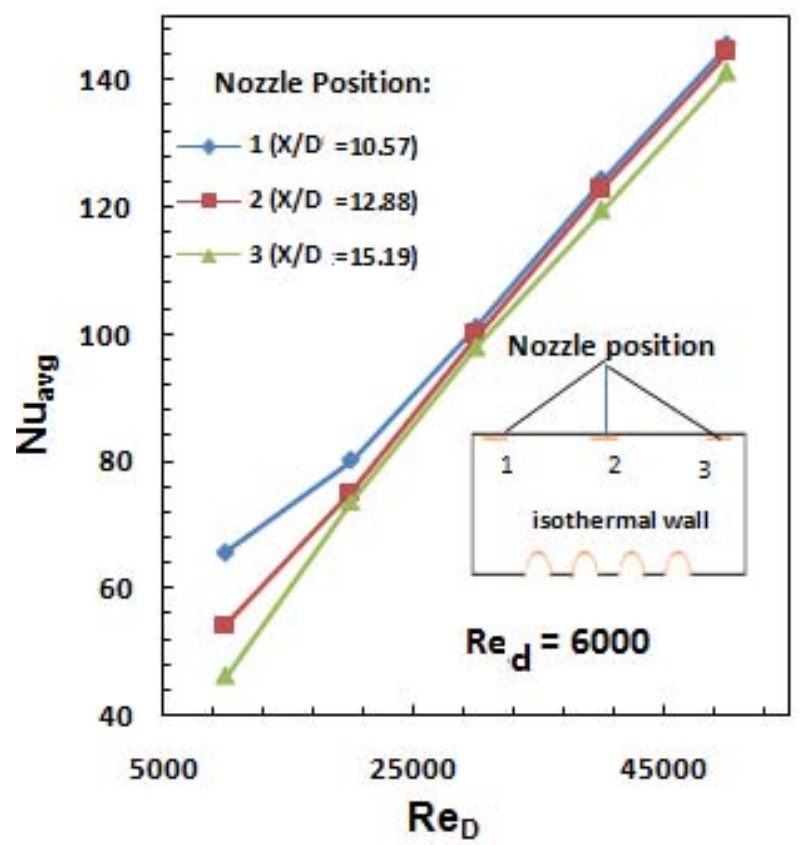

Fig.6. Variation of average Nusselt number with duct Reynolds number. 
The nozzle Reynolds number $\left(\operatorname{Re}_{\mathrm{d}}\right)$ is fixed and duct Reynolds number $\left(\operatorname{Re}_{\mathrm{D}}\right)$ is varied from 10.000 to 50000. It has been observed that the Nusselt number increases linearly with the duct Reynolds number for different positions of the nozzle. With respect to the position of the nozzle, high heat transfer occurred for the nozzle closer to the inlet (position 1) of the duct. At duct Reynolds number equal to 10000 , the average Nusselt number has been found to be $20.73 \%$ and $42.1 \%$ more in comparison to the other two nozzle positions. Velocity and temperature contours are shown in Fig.7 for different positions of the nozzle. It is observed from Fig.7a that the duct and nozzle flows are mixed with each other before reaching the convex dimpled surface. The dimples reduce the cross section of the flow and consequently the flow is accelerated so that high velocity gradients are seen in the upstream of the convex dimple surface. The flow then finds a sudden expansion in the downstream which leads to a reverse flow because of which a recirculation zone is created. The strong recirculation zone helps in bringing more cold fluid from the main stream and effectively mixes with the hot fluid. Therefore, the heat transfer rate increases. When the nozzle is placed at position 1, the duct flow pushes the flow from the nozzle towards the downstream direction so that a stronger recirculation zone is created towards the downstream direction of the entire convex dimple surface which is shown in Fig.7a.

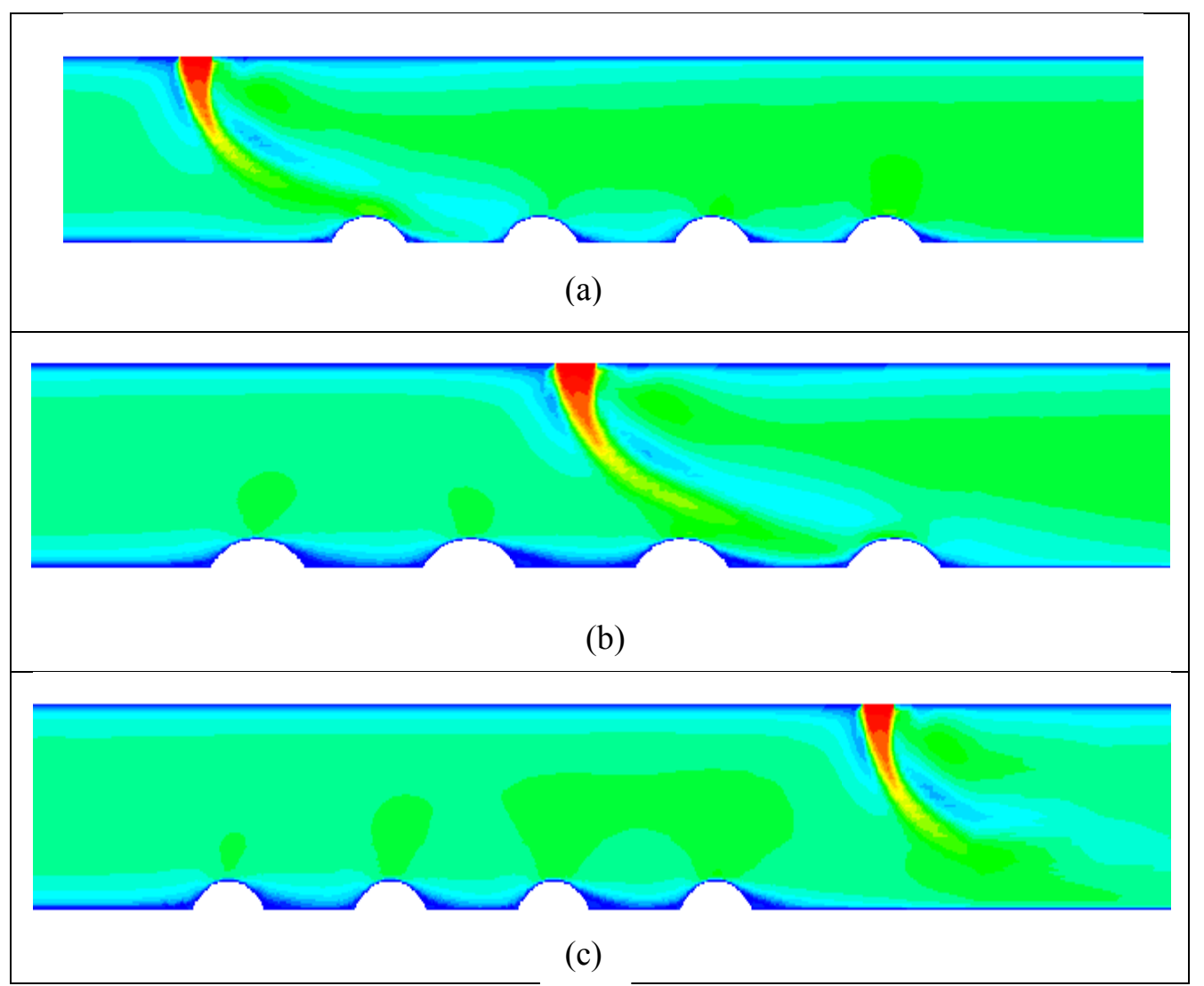

Fig.7. Velocity contours at $\mathrm{Re}_{\mathrm{D}}=10.000$, and $\mathrm{Re}_{\mathrm{d}}=6000$

Nozzle position 1 (Fig.a); Nozzle position 2 (Fig.b) and Nozzle position 3 (Fig.c).

For nozzle position 2, the high energy created due to cross flow comes in contact only with the last dimple surface along the mean flow of the duct (Fig.7b). Therefore, heat transfer is less compared to nozzle position 1. No dimples comes in contact with the high energy cold fluid created due to cross flow for nozzle position 3, which leads to least amount of heat transfer compared to other two positions of the nozzle. Due to high heat transfer at position 1 , it is chosen for further studies. 


\subsection{Effect of duct Reynolds number and nozzle Reynolds number for convex dimpled surface}

Figure 8 illustrates the effect of the nozzle Reynolds number on the average Nusselt number. It is clear from the figure that at lower duct Reynolds number (i.e. $\mathrm{Re}_{\mathrm{D}}=10000$ and 20000), the Nusselt number has been increased by $59.8 \%$ and $32.8 \%$, respectively, when the nozzle Reynolds number is increased from 6000 to 12000. Also, the Nusselt number increased with the duct Reynolds number. For example, at $\mathrm{Re}_{\mathrm{D}}=6000$, the Nusselt number was increased by $121 \%$ as the duct Reynolds number is increased from 10000 to 50000 . This proves that the Reynolds number plays a very important role in the heat transfer prediction in such type of flows.

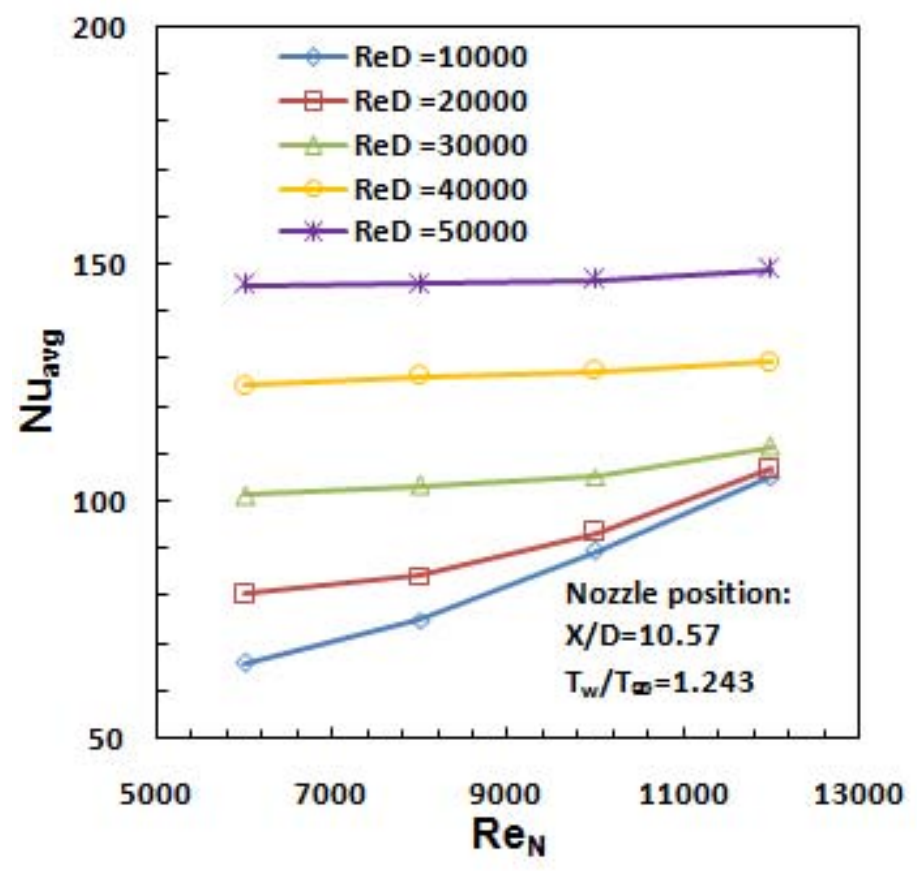

Fig.8. Average Nusselt number vs. nozzle Reynolds number at various duct Reynolds numbers.

However, at higher duct Reynolds number, the rate of increase of the Nusselt number reduced. It has been observed that the Nusselt number is increased by $10 \%, 3.9 \%$ and $2.2 \%$ for the duct Reynolds number of 30000,40000 and 50000, as the nozzle Reynolds number is varied from 6000 to 12000 . This is due to the fact that the high momentum of the duct flow (at high duct Reynolds number) blows the low momentum fluid from the jet. Thus, the low momentum jet fluid is not able to reach the hot surface to transfer heat from it. So, there is no appreciable variation in the Nusselt number with the nozzle Reynolds number at higher duct Reynolds number. The results of Fig. 8 can be better explained by plotting the velocity contours. The flow from the nozzle as well as the main flow superimposed and produced a net flow which is responsible for the overall heat transfer from the hot dimpled surface. In Fig.9, it is seen that the nozzle fluid touches the bottom hot surface, and thus, the heat from the bottom isothermal surface is transferred by the combined convective effect of the main fluid as well as the jet fluid. However, in Fig.9b, it is observed that the nozzle fluid is blown with the main flow as the duct Reynolds number is increased. An intense blow off of the nozzle fluid is seen at higher duct Reynolds numbers (Figs 9c - d). Therefore, it is evident that the nozzle flow is blown away by the high momentum of the main flow without reaching the hot surface for higher duct Reynolds numbers. Hence, the effect of nozzle flow is not felt at the bottom and no appreciable change in heat transfer happened. 


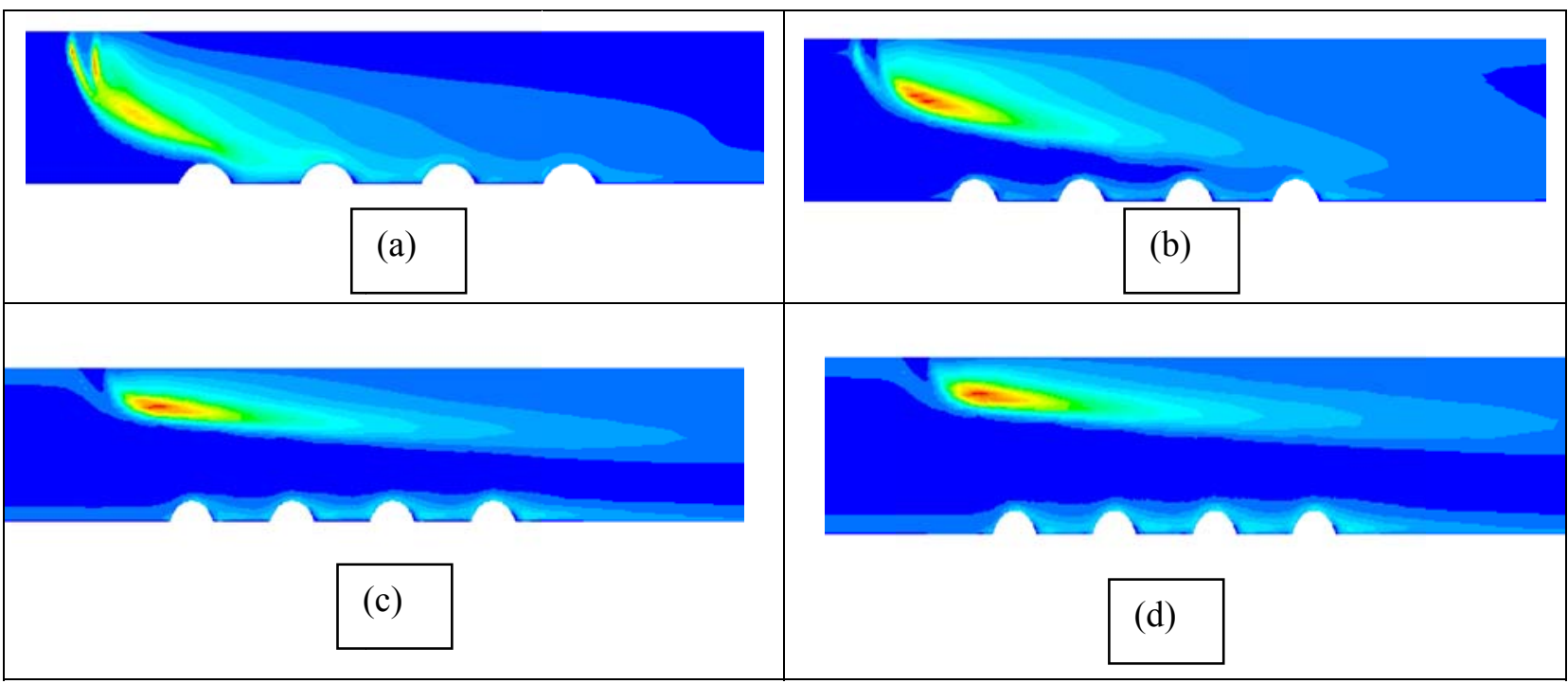

Fig.9. Velocity contours in the $X-Y$ plane at $\operatorname{Re}_{\mathrm{d}}=6,000$ for (a) $\operatorname{Re}_{\mathrm{D}}=10000$; (b) $\operatorname{Re}_{\mathrm{D}}=20,000$; (c) $\operatorname{Re}_{\mathrm{D}}=40000$; (d) $\operatorname{Re}_{\mathrm{D}}=50000$.

\subsection{Effect of dimple surface and cross flow on heat transfer}

The cross flow effect is compared with no cross flow effect on the heat transfer prediction. Here, without cross flow means no jet flow. The variation of the average the Nusselt number with the duct Reynolds number is plotted on Fig. 10 for cross flow and without cross flow. For $\operatorname{Re}_{\mathrm{D}}=10000$, the Nusselt number is enhanced by $46.5 \%$. For higher values of $\mathrm{Re}_{\mathrm{D}}$, an increase of Nusselt number lies in the range 5 $10 \%$. With the help of a cross flow, the turbulence level inside the duct increases creating a stronger recirculation zone. The recirculation zone brings more cold fluid from the duct main stream and effectively mixes with the hot fluid, thereby increasing the heat transfer rate.

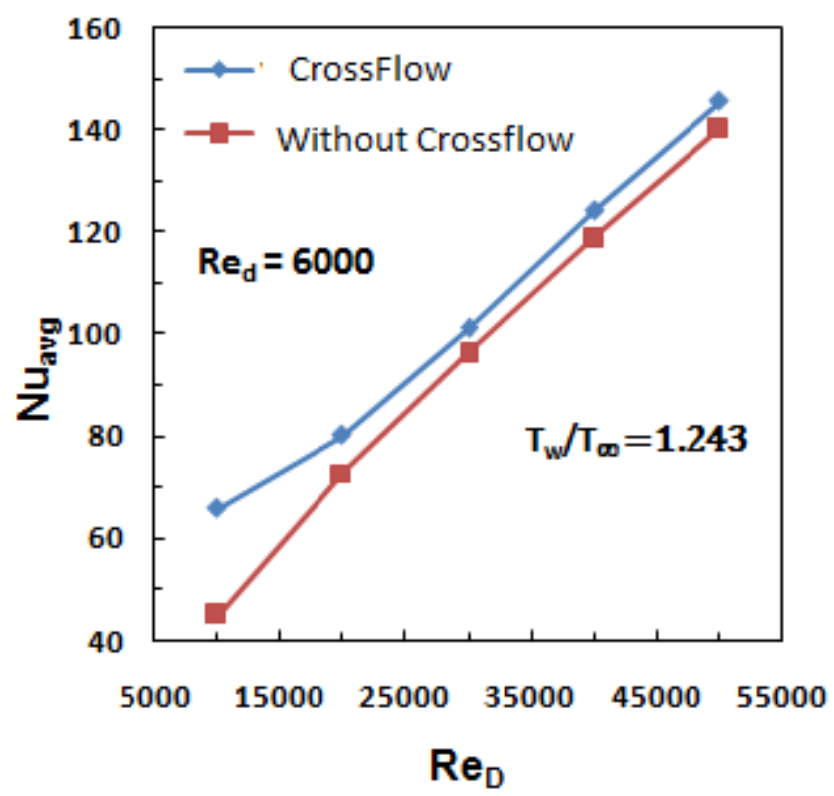

Fig.10. Effect of cross flow on heat transfer prediction. 


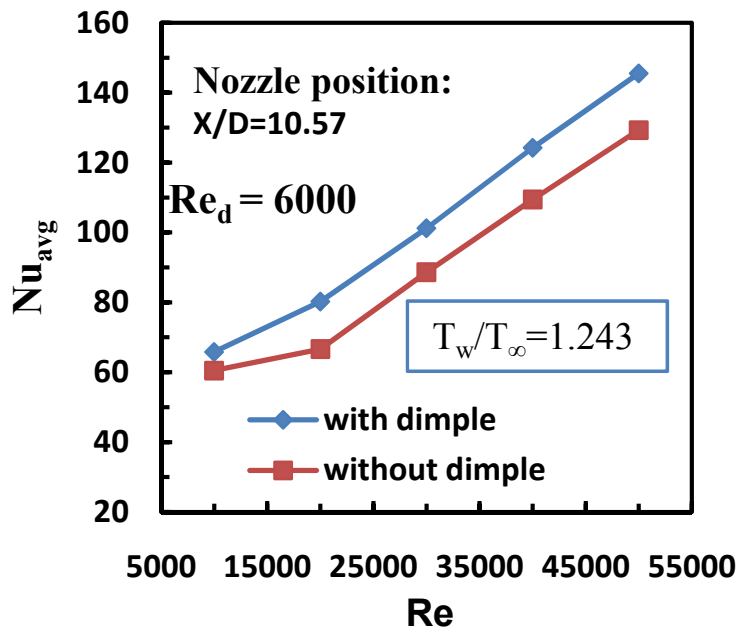

Fig.11. Effect of dimpled surface on heat transfer prediction.

Figure 11 shows the effect of the dimple surface on the prediction of average Nusselt number for different value of the duct Reynolds number. It is observed that addition of dimples on the flat plate affects the heat transfer rate. It increases considerably. This happens due to the fact that addition of dimples increases the exposed surface area for heat transfer. Also, addition of dimples acts as an obstacle to the inlet flow, which increases the turbulence. As we know turbulence increases mixing, which results in an increase in the heat transfer rate.
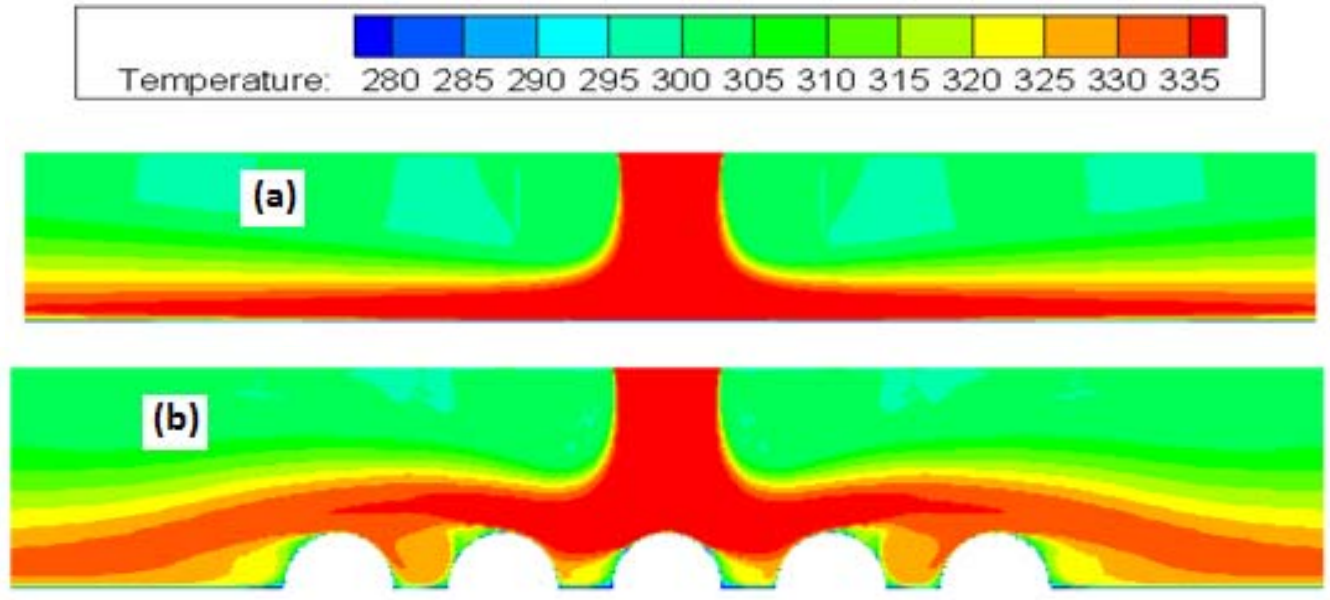

Fig.12. Temperature contour of flat plate attached with (a) No dimple and (b) hemispherical dimples.

Also, the edge of the dimple thins the boundary layer and enhances heat transfer between the flat portions between the dimples. When the jet impinges on the hemispherical dimples, the recirculation effect is more pronounced. It is well known that the thinner boundary layer is capable of dissipating more heat as compared to a thicker boundary layer. A lower temperature in the inter protrusion gaps can be seen from the Fig. 12 due to higher velocity magnitudes so that the fluid from the main flow can be drawn rigorously at higher momentum into these regions to enhance the heat transfer rate. Hence, the inter protrusion spacing as well as the size of the convex dimples play important role in the rate of heat transfer enhancement. Optimization for these parameters along with the nozzle and duct Reynolds number will be helpful in obtaining maximum possible heat transfer.

\section{Conclusions}

CFD simulations for heat transfer prediction from a mini rectangular duct were performed with a hemispherical convex dimple surface with cross flow. Results were also compared with a plane surface and 
without cross flow. The major parameters such as the nozzle position, duct Reynolds number and nozzle Reynolds number were considered to investigate their effect on the average heat transfer from the rectangular channel. Enhancement of heat transfer is found to be more, when the cross flow approach is adopted instead of the non-cross flow approach. It was observed that heat transfer is found to increase significantly by the addition of convex dimples on the flat surface. The cross flow effect drastically increased heat transfer when compared to no cross flow. When the nozzle is positioned at a distance 10.57 times the hydraulic diameter of the duct from the inlet, maximum enhancement of heat transfer from the hot surface took place compared to other two positions of the nozzle (i.e. $X / D=12.88$ and 15.19). For a constant nozzle Reynolds number $\left(\mathrm{Re}_{\mathrm{d}}=6000\right)$, the average Nusselt number is improved by $148.7 \%$, when the duct Reynolds number is varied from 10,000 to 50,000 . Heat transfer increased with an increase in the duct as well as Nozzle Reynolds numbers.

\section{Nomenclature}

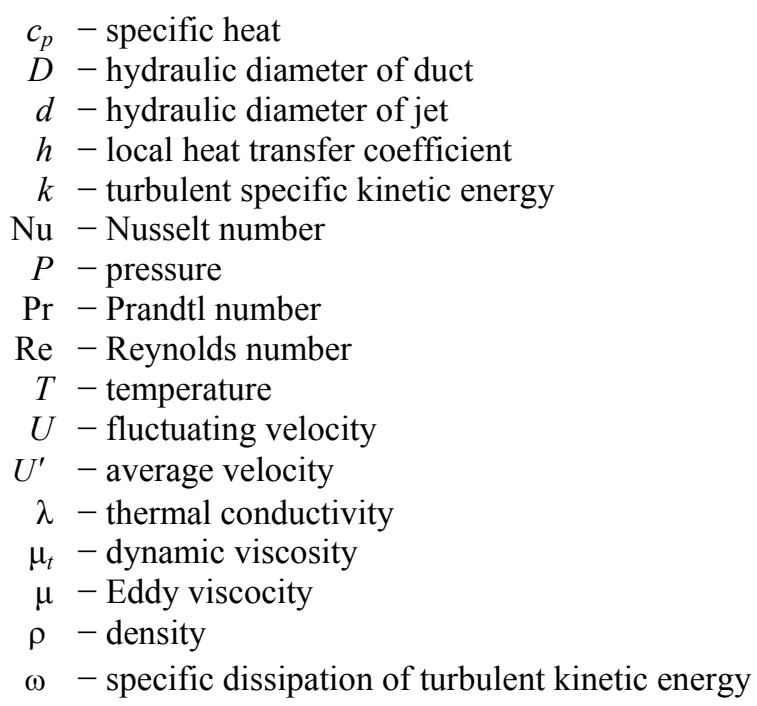

\section{References}

[1] Dittus F.W. and Boelter L.M.K. (1930): Heat transfer in automobile radiator of the tubular type. University of California at Berkley Publ. Eng., vol.2, pp.443-461.

[2] Gamrat G., Faver-Marinet M. and Asendrych D. (2005): Conduction and entrance effects on laminar liquid flow and heat transfer in rectangular micro-channels. - Int. J. Heat and Mass Transfer, vol.48, pp.2943-2954.

[3] Ma J., Li L., Huang Y and Liu X. (2011): Experimental studies on single-phase flow and heat transfer in a narrow rectangular channel. - Nuclear Engineering and Design, vol.241, pp.2865-2873.

[4] Sudo Y., Miyata K., Ikawa H., Ohgawara M. and Kaminaga M. (1984): Core heat transfer experiment for JRR-3 to be upgraded at 20MWt: Part1 Differences between up-flow and down flow for rectangular vertical flow channel. - JAERI-M 84-149.

[5] Sudo Y., Miyata K., Ikawa H., Ohkawara M. and Kaminaga M. (1985): Experimental study of differences in single-phase forced convection heat transfer characteristics between up-flow and down flow for narrow rectangular channel. - Journal of Nuclear Science and Technology, vol.22, pp.202-212.

[6] Dewan A., Patro P., Khan I. and Mahanta P. (2010): Effect of fin spacing and material on performance of circular pin fin heat sink. - Proc. of IMechE, Part A, Journal of Power and Energy, vol.224, pp.35-46.

[7] Dewan V., Bharti V., Mathur U.K., Saha P. and Patro A. (2009): Comparison of tapered and straight circular pin fin compact heat exchangers for electronic appliances. - Journal of Enhanced Heat Transfer, vol.16, No.3, pp.301-314.

[8] Wang F., Zhang J. and Wang S. (2012): Investigation on flow and heat transfer characteristics in rectangular channel with drop-shaped pin fins. - Propulsion and Power Research, vol.1, No.1, pp.64-70. 
[9] Chyu M.K., Hsing Y.C. and Natarajan V. (1998): Convective heat transfer of cubic pin fin arrays in a narrow channel. - ASME Journal of Turbomachinery, vol.120, No.2, pp.362-367.

[10] Zuckerman N. and Lior N. (2006): Jet impingement heat transfer: physics, correlations, and numerical modelling. - Advances in Heat Transfer, vol.39, pp.565-631.

[11] Sakakibara J., Hishida K. and Maeda M. (1997): Vortex structure and heat transfer in the stagnation region of an impinging plane jet. - Int. J. Heat Mass Transfer, vol.40, pp.3163-3176.

[12] Gardon R. and Akfirat J.C. (1965): The role of turbulence in determining the heat transfer characteristics of impinging jets. - Int. J. Heat Mass Transfer, vol.8, pp.1261-1272.

[13] Didden N. and Ho C.M. (1985): Unsteady separation in a boundary layer produced by an impinging jet. - J. Fluid Mech., vol.160, pp.235-256.

[14] Gauntner J., Livingood N.B. and Hrycak P. (1970): Survey of Literature on Flow Characteristics of a Single Turbulent Jet Impinging on a Flat Plate. - NASA, TN D-5652, Lewis Research Center, USA.

[15] Ho C.M. and Nosseir N.S. (1981): Dynamics of an impinging jet, part 1: the feedback phenomenon. - J. Fluid Mech., vol.105, pp.119-142.

[16] Jambunathan K., Lai E., Moss M.A. and Button B.L. (1992): A review of heat transfer data for single circular jet impingement. - Int. J. Heat Fluid Flow, vol.13, pp.106-115.

[17] Kanokjaruvijit K. and Martinez-Botas R.F. (2005): Jet impingement on a dimpled surface with different cross flow schemes. - Int. J. Heat Mass Transf., vol.48, pp.161-170.

[18] Gau C.M. Chung (1991): Surface curvature effect on slot-air jet impingement cooling flow and heat transfer process. - J. Heat Transf., vol.113, pp.858-864.

[19] Salewski M., Stankovic D. and Fuchs L. (2008): Mixing in circular and non-circular jets in cross flow. - Flow, Turbul. Combust, vol.80, pp.255-283.

[20] Sparrow E.M., Goldstein R.J. and Rouf M.A. (1975): Effect of nozzle-surface separation distance on impingement heat transfer for a jet in a cross-flow. - ASME J. Heat Transfer, vol.97, pp.528-533.

[21] Bouchez J.P. and Goldstein R.J (1975): Impingement cooling from a circular jet in a cross flow. - Int. J. Heat Mass Transfer, vol.18, pp.719-730.

[22] Goldstein R.J. and Behbahani A.I. (1982): Impingement of a circular jet with and without cross flow. - Int. J. Heat Mass Transfer, vol.25, pp.1377-1382.

[23] Barik A.K., Mukherjee A. and Patro P. (2015): Heat transfer enhancement from a small rectangular channel with different surface protrusions by a turbulent cross flow jet. - International Journal of Thermal Sciences, vol.98, pp.32-41.

[24] Wang L., Sunden B., Borg A. and Abrahamsson H. (2011): Control of jet impingement heat transfer in cross flow by using a rib. - Int. J. Heat Mass Transf., vol.54, pp.4157-4166.

[25] Launder B.E. and Spalding D.B. (1974): The numerical computation of turbulent flows. - Comp. Meth. Appl. Mech. Eng., vol.3, No.2, pp.269-289.

[26] Slicher C.A. and Rouse M.W. (1975): A convenient correlation for heat transfer to constant and variable property fluids in turbulent pipe flow. - Int. J. Heat Mass Transf., vol.18, pp.677-683.

[27] Sieder E.N. and Tate G.E. (1936): Heat transfer and pressure drop of liquids in tubes. - Ind. Eng. Chem., vol.28, pp.1429-1436.

[28] Dittus F.W. and Boelter L. M. K. (1930): Heat transfer in automobile radiators of the tubular type. - The University of California Publications on Engineering, vol.2, pp.443-461, Reprinted in Int. Commun. Heat Mass., vol.12 (1985), pp.3-22. 